\title{
Social Support And Gender As Predictors Of Readiness To Combat Crime Among Police Officers In Osun State Command, Nigeria
}

\author{
Olusola Abayomi Ayegun \\ Department of Psychology, Obafemi Awolowo University, \\ Ile-Ife, Osun State, Nigeria \\ Adeboye Titus Ayinde PhD \\ Department of Psychology, Obafemi Awolowo University, \\ Ile-Ife, Osun State, Nigeria
}

\begin{abstract}
Police effectiveness in crime combat may not necessarily depend on how well they are remunerated or the quantity of equipment made available to them, but the quality of cooperation receives from the members of the public and their sexual orientation may also lend credence. Therefore, this study examined the extent to which social support and gender predict readiness to combat crime among police officers. This was done with a view to identifying psychosocial factors that predict readiness to combat crime among police officers in Osun State Command. The study used primary data embedded in descriptive survey design. Multistage sampling technique was adopted in determining and obtaining data from the sample population. Three police area commands namely Osogbo, Ile-Ife and Ilesa were purposively selected for the study. The sample consisted 258 police officers who were selected using the stratified random technique with different units of Command as a basis of stratification. Two instruments: Multidimensional Scale of Perceived Social Support (MSPSS) and Readiness to Combat Crime Scale (RCCS). Data collected were analysed using both descriptive (percentage count) and inferential statistics (linear regression and t-test). The results showed that social support significantly predicted readiness to combat crime among police officers in Osun State Command $[F(1,226)=17.538 ; p<0.05]$. However, there was no significant gender difference in readiness to combat crime among police officer in Osun State Command $[t(224)=0.186 ; p>0.05]$. The study concluded that social support successfully predicted readiness to combat crime, while gender had no influence on readiness to combat crime among police officers in Osun State Command.
\end{abstract}

Keywords: Social Support, gender, crime combat, police readiness, Nigeria

\section{Background to the Study}

\section{INTRODUCTION}

What is today known as the Nigeria Police Force came into being in 1861when the British Consul with the permission from his principal in London established a consular guard comprising 30 men. The force then grew out of numerous constabulary forces in the late 19th century to the present day modern force. It was created primarily not to protect the common interests by any stretch of the imagination but to protect and safeguard those trading interests of the colonial masters - missionary enterprise and slave trade. Nigeria was colonized piecemeal and therefore required force to quench the native attaché. 
Societies all over the world expand and develop continuously; as such human relationship and activities also expand (New World Encyclopaedia, 2013). The results of the dynamism of the growing population often give room for crimes. Both developed countries (such as Great Britain and the United States) and developing countries (such as Malaysia and Ghana) strive to establish and develop institutions that can ensure peace as well as security of lives and property of its citizenry. This is also true of the Nigerian state where the Nigerian Police Force as an institution has been established by law and given the responsibility to protect the citizens and ensure peace and stability within the Nigerian polity. However, several decades after its creation or formation, the goal of achieving peace and security through the force appeared to be elusive. Several factors may be responsible for the inability of the Nigerian police in combating crime and ensuring peace and security. Some of these factors such as poor funding, remuneration, corruption, lack of equipment to mention just a few have been investigated, but the problems seem unabated.

Crime combat could be described as a process or an action taken by the police to fight against criminal activities and crime is like other concepts in social sciences, which have no generally accepted definition. Crime in the social and legal framework is the set of facts or assumptions that are part of a case in which there were committed acts punishable under criminal law (Adebayo, 2013). In criminal law, crime is an act of omission which attracts sanctions such as fines, imprisonment or even death (Adebayo, 2013). According to Oxford Dictionary of Sociology (Scott and Marshall, 2009) "a crime is held to be an offence, which goes beyond the personal and into the public sphere, breaking prohibitory rules or laws, to which legitimate punishments or sanctions are attached, and which requires the intervention of a public authority. For a crime to be known as such, it must come to the notice of, and be processed through, an administrative system or enforcement agency. It must be reported and recorded by the police or other investigators. It may then become part of criminal statistics; may or may not be investigated, and may or may not result in a court case.

Readiness is the preparedness from the perspective of psychosocial makeup towards a focused programmed. That is, the preparation towards a necessitated activity in order to achieve the objectives of an institution or establishment. In other words, it is the availability of a desired latent trait towards the actualization of certain goals and objectives. The actualization of behavioural readiness depends on employee's ability to meet up with the psychological and attitudinal demands of the tasks. Readiness to combat or fight crime in this study refers to the degree to which Police Officers themselves perceive their readiness in fighting crimes. A similar concept - readiness to work describes the process of judging whether an individual is psychological, physically and emotionally ready to return to his/her functional position at work and is often used in assessing individuals who have just recovered from a traumatic experience such as accident, bereavement or some kind of loss of the other. Components of work readiness include six specific capabilities which are self-awareness, receptiveness, drive, self-assurance, resilience and information (Impetus, 2014). For a police officer, essential characteristics for work include physical fitness (Williams, 2002) as well as mental alertness, ability to make accurate split-second decisions that may be ethically and legally complex and may call for advanced tactics and coordination (Ray, 2016).

Physical readiness is defined as the ability of a police officer to meet the physical demands of any combat or duty position, accomplish the mission, and continue to fight and win. Physical readiness is, in turn, essential to combat crime and prepares police officers and units physically to be successful in the conduct of full-spectrum operations. Secondary goals of Police Physical readiness training are to instil confidence and the will to win; develop teamwork and unit cohesion; and integrate aggressiveness, resourcefulness, and resilience. The physical readiness 
training system brings police officers to a state of physical readiness through a systematic program of drills and activities specifically designed to enhance performance. Meanwhile, one element of Police Officers' readiness to combat crimes is Physical Fitness. This is one of the most requirements for recruiting into the Nigeria Police Force because a policeman that is ready to confront a criminal or chasing an armed robber must be physically fit.

Mental readiness in police is the state of being mentally prepared and this can either mean you are ready to learn from the situation you are in or can put your knowledge skills and attitudes into practice to optimally deal with the situation you are in and police psychological readiness to combat crime is the ability to read and study situations around and predict what may likely happen. Moreover, the importance of mental fitness/Alertness in police readiness to combat crime cannot be overemphasized. It may also describe the state of psychosocial well-being that goes beyond the absence of disease or sickness. It means having a positive sense of how we feel, think, and act, which improves our ability to enjoy life. It contributes to our innate ability to self-determine. Mental alertness is experienced when our needs for competence, autonomy and relatedness are met. In this regards, a police officer that is ready to fight crime must have a very sound mental alertness and this equally suggests the ability to efficiently respond to life's challenges, and effectively restore and sustain a state of balance.

Social support is important to police officers who are interested in good physical and mental health. A support recipient's perception, the specific supportive actions received and the extent to which a person is integrated within a social network is very important. In this study, social support refers to the perception of support received from the Government, Cooperate bodies, individuals and society generally and it is also the physical and emotional comfort given to people by family, friends, co-workers and others. It is known that police officers are part of a community of others who love and care for them, and value and think well of them (Alonso \& Coe, 2001). To police officers, Support can come in many different forms; experts who study human relationships have identified three main types of social support: these are emotional support, practical help and sharing points of views. Cohen and Wills 1985 on the other hand, describe two main types of social support: Structural social support, which refers to the quality of support received or perceived; and functional social support, which refers to the functions, or actions that provider performs when helping an individual. Given this reality, it could be hypothesised that the police officers who enjoy adequate and necessary social support would display the readiness to combat crime.

Gender is equally a social factor capable of predicting readiness to combat crime among police officer. This refers to an individual's inner sex or psychological sense of being a male or female irrespective of one's (outer) sex identity as determined by one's sexual organs. In this regards, gender roles refer to the set of attitudes and behaviours socially expected from the members of a particular gender identity. Gender roles, unlike natural human genders, are socially constructed. They may reflect natural gender aspirations of the members of that gender identity, or they may be politicized and manipulated, which then result in the oppression of people.

\section{Statement of the Problem}

The recent upsurge in violent crimes in Nigeria seems to have created enormous uncertainty in the security of lives and property of individuals and of social stability in general. The incidents of traditional crimes such as armed robbery, arson, drug trafficking and abuse, murder, kidnapping, rape, hired assassinations and ritual killings are examples of the most serious and violent crimes which have been on the increase in the recent past. The officers and men of the Nigerian police seem helpless in the face of this enormous criminal upsurge as a result of 
challenges inherent in the system, which seems to undermine the passion and motivation of the police officers to effectively carry out the task of crime fighting. The police should be able to stand as a viable force in maintaining the sanity of life within the state and this makes it a thing of interest to examine the factors that predict the personal motivations to combat crime in the State.

Meanwhile, several studies (Onyeozi, 2005; Omideyi, 2012; Fieder, 2012; Famutimi, 2014) have investigated problems confronting Nigerian police officers looking at it from external perspectives. However, little or none attention has been paid to the readiness of police officers in combating crime in the literature as there is a dearth of literature addressing this particular construct. Thus, the study takes up the challenge to investigate the readiness to combat crime among police officers considering the socio-demographic factors that could predict the concept.

\section{Acquired Needs Theory}

\section{LITERATURE REVIEW}

The acquired needs theory was proposed by David McClelland who proposed that different needs are acquired by individuals throughout their lifetime. He proposed three specific areas of need which are: need for achievement (nAch) - the desire to accomplish something difficult, attain a high standard of success, master complex tasks and surpass others; need for affiliation (nAff) - desire to form close personal relationships, avoid conflict, and establish warm friendships; and need for power (nPow) - the desire to influence or control others, be responsible for others, and have authority for others (Visen \& Priya, 2010).

McClelland believes that early life experiences determine whether people acquire these needs and are influenced by reinforcement behaviour received in childhood. If the child is reinforced to do things independently, he may develop strong sense of achievement motivation, if reinforced for warm, human relationships, the need for affiliation develops as an adult while if he gains satisfaction from controlling others, the need for power will be evident as an adult (Visen \& Priya, 2010). The acquired needs theory can strongly influence commitment to combating crime in later life. Childhood experiences of how police officers fight crime and the development of an idealised mind-set of how dignifying the art of crime fighting is or the desire to keep the community safe can motivate the individual to be consistently motivated towards keeping the community sane and safe and thus such will be willing to fight crime mentally, physically and psychologically.

\section{Social Support Theory}

Barnes (1954) was the first to describe patterns of social relationships that were not explained by families or work groups. Cassel (1976) found a relationship with health. Social support served as a "protective" factor to people's vulnerability on the effects of stress on health. Social networks are closely related to social support. Nevertheless, these terms are no theories per se. Social Support and Social Networks are concepts that describe the structure, processes and functions of social relationships. Social networks can be seen as the web of social relationships that surround individuals.

Social support is associated with how networking helps people cope with stressful events. Besides, it can enhance psychological well-being. Social support distinguishes between four types of support (House, 1981). Emotional support is associated with sharing life experiences. It involves the provision of empathy, love, trust and caring. Instrumental support involves the provision of tangible aid and services that directly assist a person in need. It is provided by close friends, colleagues and neighbours. Informational support involves the provision of 
advice, suggestions, and information that a person can use to address problems. Appraisal support involves the provision of information that is useful for self-evaluation purposes constructive feedback, affirmation and social comparison.

Social relationships have a great impact on health education and health behaviour. There is no theory adequately explaining the link between social relationships and health. Closely related to health components of social relationships are social integration, social network and social support (Berkman et al., 2000). Social integration has been used to refer to the existence of social ties. Social network refers to the web of social relationships around individuals. Social support is one of the important functions of social relationships. Social networks are linkages between people that may provide social support and that may serve functions other than providing support (Glanz et al., 2002). For promoting health different interventions can be used. Therefore being able to understand the impact of social relationships on health status, health behaviours and health decision making are very important. Identification of the importance of networks or training of people in networks are applications of the approach of social support.

Social support is important to many people interested in physical (for example mortality) and mental health (for example depression). As a result, there have been over 45,500 articles, chapters, and books published on social support across a wide range of disciplines including psychology, medicine, sociology, nursing, public health, and social work. There are three distinct sub-types of social support and each has different links to health. A support recipient's perception of social support, the specific supportive actions received, and the extent to which a person is integrated within a social network. In addition, there are three main types of causes of social support the personality of the support recipient, the objectively supportive aspects of support providers, as well as the relationships between specific support recipients and providers. A variety of theories of social support have been proposed. For example, one theory describes how social support helps people cope with stressful events. Another theory describes how social support maintains well-being in the absence of stress. A third theory describes how social support becomes part of an adaptive personality profile throughout a person's life.

There are three subtypes of social support: perceived support, enacted support, and social integration (Barrera, 1986). Perceived support refers to a recipient's subjective judgment that providers will offer (or have offered) effective help during times of need. Enacted support (also called received support) refers to specific supportive actions (for example, advice or reassurance) offered by providers during times of need. Social integration refers to the extent to which a recipient is connected to a social network. Family relationships, friends, and membership in clubs and organizations contribute to social integration. Surprisingly, these three forms of social support are not strongly related to each other and each has different patterns of correlations with health, personality, and personal relationships (Barrera, 1986; Uchino, 2009). For example, perceived support is consistently linked to better mental health whereas enacted support and social integration are not (Barrera, 1986; Uchino, 2009). In contrast, social integration has been linked consistently to physical health outcomes (for example mortality, heart disease) (Uchino, 2009). Enacted support has not been linked consistently to either physical or mental health (Barrera, 1986; Uchino, 2009). If anything, enacted support has been linked to worse mental health (Bolger, Zuckerman \& Kessler, 2000). There are three main types of causes of perceived support recipient trait influences, provider influences, and relational influences (Lakey, 2010, Lakey, McCabe, Fisicaro \& Drew, 1996). These can be defined and their strength can be measured when the same set of support recipients rate the same set of providers on supportiveness. Recipient influences reflect 
differences among recipients in their perceptions of providers, averaged across providers. For example, Recipient A might see all providers as more supportive than Recipient B. Because recipients are rating the same providers, we know that average differences among recipients do not reflect the characteristics of providers, but instead, reflect the trait-like personality characteristics of recipients. Provider influences reflect agreement among recipients that some providers are more supportive than other providers. As such, these influences reflect the extent to which providers are objectively supportive (that is, recipients agree on who is most supportive). Relational influences reflect systematic disagreement among recipients about the relative supportiveness of providers. For example, Recipient A might see Provider A as more supportive than Provider B, but Recipient B might see provider B as more supportive than provider A. This is the aspect of support that is a matter of personal taste, in the same way, that different people have different opinions about which works of art are better or worse.

\section{Social Support and Readiness to Combat Crime}

Social support is a significant factor in the job performance of individuals in the workplace (Ling, 2014). It can also moderate the influence of stress, role ambiguity and role conflict on job performance (Ling, 2014) implying that the provision of strong social support can serve as a strong motivational factor to mitigate any discontent employees may want to display as a result of other challenges that may arise in the course of work.

Studies have indicated the absence of adequate social support among officers of the Nigerian Police Force (Adebayo, 2013; Karimu, 2015). Adebayo (2013) reported the inadequate equipment and motivation, poverty, unemployment rate and the breakdown of family values among other factors have made crime prevention and control a difficult task. The police are poorly motivated, with poor welfare conditions, low chances of promotion, and underfunding have left the officers and rank demoralised and minimally willing to engage in the task of combating crime within the country (Adebayo, 2013). This was corroborated in the report of Karimu (2015) who indicated poor career growth system, poor welfare conditions, poor and delayed payments of remunerations and entitlements, lack of necessary equipment and shortage of manpower and poor training facilities have dampened the morale of the officers and men of the Nigerian police force and weakened their resolve to work effectively in the protection of lives and properties within the country.

\section{Gender and Readiness to Combat Crime}

Aremu and Tejumola (2008) made an assessment of emotional intelligence among Nigerian Police officers considering a variety of demographic variables. The outcome of their work showed that emotional intelligence among the police officers was not influenced by any of the following variables: gender, age, job status (officer or non-officer), marital status or length of service. This gives an indication that emotional intelligence could not be traced to demographic factors in the place of work. This finding was corroborated by Ezeogu (2016) who reported the absence of gender difference in job performance among police officers.

In summary, the literature review shows that social support and gender have a diverse influence on work-related outcomes. Studies make support for the positive influence of perceived social support on job performance and organisational commitment, however, there were mixed explanations on the gender difference in job performance. This study seeks to shed more light on the influence of these characteristics especially with respect to the readiness to combat crime among police officers. 


\section{METHODOLOGY}

This chapter presents the research design and methodology that will be used for the study. It contains detailed descriptions of the methods, respondents' selection procedure, scoring, validity and reliability of the research instruments and method of data analyses.

\section{Research Design}

The study adopted a descriptive survey research design to examine the relationship between the variables of interest. The independent variables were gender and social support, while the dependent variable is readiness to combat crime.

\section{Population of Study}

The targeted population for this study is Nigerian Police officers in Osun State Command. Osun State comprises three Senatorial districts and 30 local government areas plus an area office. Each local government comprises a single division and each division comprises different units and posts which cover several localities. The Command comprises 10 units divided as follows: Special Anti-Robbery Squad (SARS), Surveillance and Intelligence, Anti-Car theft, Homicide, Anti-Kidnapping, Legal/Prosecution, Anti-fraud/Anti-Vice, Anti-Human trafficking/Family Unit, Patrol $\backslash$ Guard and Police Anti-Bomb Squad. A total of 5,500 police officers constitute Osun State command (as at May 31, 2016) (Source: Nigeria Police, Oshogbo).

\section{Sample and Sampling Technique}

The study adopted a multistage sampling technique in the process of collection of data. The sampling technique includes purposive and stratified sampling techniques. First, the three Police area commands in Osun State were purposively selected because all units within the State Police command were well represented in each area command. The Osogbo command has a total of 360 police officers; Ilesha has 194 officers while Ife has 172 officers. This makes a total of 726 officers in the three area commands combined divided into units as follows: Special Anti-Robbery Squad, Surveillance/Intelligence, Anti-car theft, Homicide, Antikidnapping/special protection, Legal/Prosecution, Anti-fraud and anti-vice, Anti-human trafficking and family Unit, Patrol and guard, and Anti-bomb squad. The sample population for the study was determined using Taro Yamane's formula for sample size determination (Yamane, 1967) at 5\% margin of error on a population of 726 gives $n \approx 258$ respondents.

Proportionatetly stratified sampling technique was used in sampling the respondents in each command such that Osogbo command, which has the highest number of officers, was given the highest quota given that it had the highest population of police officers in the State; followed by Ilesha and finally Ile-Ife commands. Thus, a total of 128 police officers was selected from the Osogbo command, 69 from Ilesha and 61 from Ile-Ife. Meanwhile, all the ten departments in the command are well represented in each area command and the sampling procedure also take cognizance of factors such as police officers' age and gender.

\section{Research Instrument}

Demographic variables - These includes the items seeking information about the police officers' sex, age, educational qualification, religion, years of service experience and present position in the service.

Multidimensional Scale of Perceived Social Support (MSPSS) - This is a 12-item scale that was developed by Zimet, Dahlem and Farley (1988) and measures perception of support from 3 sources: family, friends and a significant other. It comprises 3 subscales with 4 items in each subscale divided and scored as follows:

Significant Other Subscale: Sum across items 1, 2, 5, \& 10, then divide by 4 . 
Family Subscale:

Friends Subscale:

Total Scale:
Sum across items $3,4,8, \& 11$, then divide by 4 . Sum across items $6,7,9, \& 12$, then divide by 4 . Sum across all 12 items, then divide by 12 .

Responses on the scale was based on a 7-point Likert scale of (1) Very Strongly Disagree (2) Strongly Disagree (3) Mildly Disagree (4) Neutral (5) Mildly Agree (6) Strongly Agree (7) Very Strongly Agree. The authors recommend a scoring approach as follows: any mean scale score ranging from 1 to 2.9 was considered low support; a score of 3 to 5 was considered moderate support; a score from 5.1 to 7 was considered high support. The MSPSS has been reported by Zimet, Dahlem, Zimet and Farley (1988) to have good internal and test-retest reliability as well as good validity and fairly stable factorial structure.

Readiness to Combat Crime Scale (RCCS) - This consisted of a 15-item purposely designed scale designed for the study. It measures information about the respondents' physical, emotional and mental readiness to engage in activities of crime combating. Responses on the scale were based on a 5-point Likert scale of Strongly Disagree (1), Disagree (2), Undecided (3), Agree (4) and Strongly Agree (5). A high score on the scale will indicate higher levels of readiness to combat crime. Based on a pilot study conducted on a sample of 45 police officers (male $=27$, female $=15$; mean age $=40$ years) in Ile-Ife, the scale has an overall Cronbach's alpha of $0.721($ mean $=58.64$, S.D. $=6.724)$ while each of the sub-dimensions were $0.524,0.724$ and 0.609 for physical $($ mean $=19.17$, S.D. $=3.574)$, mental $($ mean $=17.52$, S.D. $=2.662)$ and emotional readiness $($ mean $=21.95$, S.D. $=2.888)$ respectively.

For validation, the instrument was submitted to four consortium experts in Tests and Measurement, Counselling, Psychology and Evaluation as to ensure the content, construct and face validity of the instrument. The final draft of the instrument was submitted to the supervisor for further scrutiny

\section{Procedure for Data Collection}

The questionnaire was administered to the respondents at the command stations during work days. Permission to carry out the study was gotten from the head of each command or the most senior officer available as at the time of visit. Copies of the questionnaire were dropped with a designated trained official in each Area Office with instructions on how they were to be completed. The trained officials helped to administer the questionnaire directly to the officers. The administration of questionnaire took two weeks in the month of January 2017.

\section{Analysis of Data}

The data collected was analysed using the statistics in two phases. The first phase was the analysis of the demographic variable of the participants using descriptive statistics such as mean, standard deviation, percentages and frequency. The second phase was the testing of the stated hypotheses, with inferential statistics accordingly. Specifically, hypotheses one was tested using Linear Regression and hypothesis two was tested using independent samples ttest.

\section{Descriptive Analysis}

\section{RESULTS}

The distribution of respondents as revealed that with regards to gender, $150(63.0 \%)$ of the respondents were male while $88(37.0 \%)$ were female. The mean age was 39.07 (S.D. $=9.87$ ) 


\section{Hypotheses testing}

Hypothesis one: Social support will not significantly predict readiness to combat crime among police officers in Osun state.

Both the independent (social support) and dependent (readiness to combat crime) variables were measured on a continuous scale, thus the hypothesis was tested using simple linear regression at .05 level of significance. The result is presented in Table 1.

Table 1 Simple linear regression of relationship between social support and readiness to combat crime among Police Officers in Osun State

\begin{tabular}{|c|c|c|c|c|c|}
\hline \multicolumn{6}{|c|}{ ANOVA } \\
\hline & Sum of Squares & $d f$ & Mean Square & $F$ & $p$ \\
\hline Regression & 994.260 & 1 & 994.260 & & \\
\hline Residual & 12812.209 & 226 & 56.691 & 17.538 & .000 \\
\hline Total & 13806.469 & 227 & & & \\
\hline \multicolumn{6}{|c|}{ Coefficients } \\
\hline & $\boldsymbol{B}$ & Std. Error & Beta & $t$ & $p$ \\
\hline (Constant) & 47.370 & 2.536 & & 18.676 & .001 \\
\hline Social Support & .168 & .040 & .268 & 4.188 & .001 \\
\hline$R=0.268 ; R^{2}=$ & $72 ;$ Adj. $R^{2}=.06$ & S.E.E. $=7.5$ & 936 & & \\
\hline
\end{tabular}

The result showed that social support significantly predicted readiness to combat crime among the respondents $[\mathrm{F}(1,226)=17.538 ; \mathrm{p}<.05]$. Further examination of the coefficients showed that Social Support significantly predicted readiness to combat crime among the Police Officers $[\beta=0.168 ; \mathrm{t}=4.188 ; \mathrm{p}<.05]$. The result also showed that there was a mild correlation between the independent variable and the dependent variable $(r=0.268)$ and the model provided a very weak prediction of the variation in the independent variable (7.2\%). Thus, the hypothesis that social support will not significantly predict readiness to combat crime among police officers in Osun State is rejected and the alternate hypothesis was accepted

\section{Hypothesis Two: There will be no significant gender difference in readiness to combat crime among Police officers in Osun state}

There are two categories of gender (male and female); hence, the hypothesis was tested using independent samples t-test at 0.05 level of significance. The result is presented in Table 2 .

Table 2 Independent samples t-test of difference in mean readiness to combat crime between male and female police officers

\begin{tabular}{|c|c|c|c|c|c|c|c|c|}
\hline Sex & $\mathbf{N}$ & Mean & $\begin{array}{l}\text { Std. } \\
\text { Dev. }\end{array}$ & $\begin{array}{c}\text { S.E. } \\
\text { Mean }\end{array}$ & $\begin{array}{l}\text { Mean } \\
\text { Diff. }\end{array}$ & $\mathbf{t}$ & df & p \\
\hline Male & 140 & 57.89 & 8.17 & 0.69 & \multirow{2}{*}{19967.} & \multirow{2}{*}{.186} & \multirow{2}{*}{224} & \multirow{2}{*}{.852} \\
\hline Female & 86 & 57.69 & 7.21 & 0.78 & & & & \\
\hline
\end{tabular}

The result shows that the male police officers had a mean readiness to combat crime score of 57.89 (S.D. $=8.17$ whereas the female police officers had a mean of 57.69 (S.D. $=7.21$ ). The mean difference was 0.20 and this was not significant [ $t(224)=0.186 ; p>.05]$. Thus, the hypothesis that there will be no significant gender difference in readiness to combat crime of Police Officers in Osun State is accepted and it can be concluded that male and female Police Officers in Osun State are not different in their readiness to combat crime. 


\section{DISCUSSION OF FINDINGS}

In order to achieve the main objective of this study, two hypotheses were postulated. The first hypothesis stated that social support will not significantly predict readiness to combat the crime among police officers in Osun State. This hypothesis was rejected as it was found that social support has a significant influence on the readiness to combat crime among police officers. The direct implication of this finding was that men of Nigerian police crave for the need for affiliation and recognition of their contributions. This finding finds support in the report of Ling (2014) who reported that social support is a strong motivational factor for work. This can be implied to mean that perception of good social support encourages the determination and commitment of police officers to the task of crime fighting and readiness to engage criminals at any time. The perception of good social support also means that the police officers desire appropriate back up in case of emergency and the need to be assured of the possibility of getting help in other areas of their lives. This could have a way of encouraging them to be more willing to engage in risky ventures knowing that they have something to fall back on if things go rough.

The second hypothesis stated that there will be no significant gender difference in readiness to combat crime of Police Officers in Osun State. The hypothesis was confirmed with no traces of gender difference in readiness to combat crime among respondents. This is an indication of the fact that police officers, irrespective of their sexual orientation choose to be professional in crime combat. They may possibly place an equal premium on social support from members of the public. The finding was corroborated by the work of Aremu and Tejumola (2008) and Ezeogu (2016) who reported the absence of gender difference in certain psychological characteristics among police officers. The development may not be unconnected with the recent clamour for more gender equity in job characteristics in the place of work. Given that gender has a significant influence on readiness to combat crime, beam more light on the need eradicate gender bias in recruitment and selection of police officers as well as ensuring equal opportunities for male and female in the promotion, assessment and other factors of work among members of Nigerian police officers.

\section{CONCLUSION}

i. Social support can successfully predict readiness to combat crime among police officers in Osun state.

ii. Male and female police officers in Osun state were not different in their readiness to combat crime.

\section{IMPLICATION OF THE STUDY}

The study aimed at improving on the existing data and contributing to the growing body of knowledge, on issues relating to the security, readiness of police to combat crime and prevention of crime in Nigeria. Specifically, the result has established that availability of social support, will contribute to the readiness of police officers in crime fighting in Osun State and Nigeria in general. Thus, this study has implications for Nigeria. For instance, the amount of information, cares, concerns and confidence repose on them by the general public will go in a long way in assisting Nigerian Police to combat crime. The management of Nigerian Police has always converse for support alongside these lines. The phrase such as 'help police to help you' or 'police is your friend' has been used to crave for the public social support and the findings of this study revealed how relevant this support is to their readiness to combat crime. Therefore, it behoves members of the public to give necessary social support to aid effective policing in Osun State and in Nigeria at large. Meanwhile and contrary to general insinuation that male officers in Nigerian police are more likely to display the readiness to combat crime compared to their female counterparts, the finding of this study revealed otherwise. The implication of 
the finding is that as long as both of them enjoying the similar support and equally motivated, they are not different in their readiness to combat crime. Consequently, gender or sex attributes should be downplayed, while emphasis should be on social support that can motivate both male and female among rank and file of the Nigerian police.

\section{LIMITATION OF THE STUDY}

The information provided and the findings in this study could be vital strategies for crime control in Nigeria especially for police officers and other security agencies that have been given the mandate to control crimes in the country. However, the study has several limitations; the fact that the sample consisted of a small size of police officers in Osun State Command only is a potential limitation. A larger sample size of police officers from other commands across the states would be good for effective generalization of results. However, this could not be obtained due to time shortage and financial constraint on the part of the researcher. Secondly, the stress involved in the administration of the questionnaires and the busy schedule as well as investigative nature of police officer's job could be potential limiting factors for the methodology.

\section{RECOMMENDATIONS}

Based on the outcomes of the study, it is recommended that further studies be carried out to examine the intercorrelations between dimensions of social support and readiness to combat crime in order to show the possible dimension of sub-level influences. Meanwhile, lack of necessary social support has dampened the morale of the police officers and men of the Nigeria police force and weaken their resolve to work effectively in the protection of lives and properties within the country. Thus, all hands must be on the desk to provide the social support needed by Nigerian Police for effective crime control.

\section{References}

Adebayo, A.A. (2013). Social factors affecting effective crime prevention and control in Nigeria. International Journal of Applied Sociology, 3(4) 71-75. DOI: 10.5923/j.ijas.20130304.01

Alonso C. \& Ceo C. (2001) "Disruptions of social relationships accentuate the association between emotional distress and menstrual pain in young women" Health Psychol. Nov:20 (6) 411 - 6.

Aremu A. O. and Tejumola T. O. (2008) Assessment of Emotional Intelligence among Nigeria Police. Journal of Social Science, 16 (3): 221-226.

Barrera, M. (1986).Distinctions between social support concepts, measures, and models. American Journal of Community Psychology, 14, 413-445.

Berkman, L. F., Glass, T., Brisette, I.,\&Seeman, T. E. (2000). “From Social Integration to Health: Durkheim in the New Millennium". Social Science and Medicine, 51, 843-857.

Bolger, N., Zuckerman, A., \& Kessler, R.C. (2000).Invisible support and adjustment to stress. Journal of Personality and Social Psychology, 79, 953-961.

Cassel, J. (1976). “The contribution of the Social Environment to Host Resistance” American Journal of Epidemiology, 104, 107-123.

Ezeogu, C.K. (2016). The influence of emotional intelligence on the job performance of police officers in Nigeria. Unpublished research submitted to the Department of Psychology, ObafemiAwolowo University, Ile-Ife, Nigeria

Famutimi, T. (2014). Sorry state of Nigeria Police. Retrieved from www.osundefender.org/?p=141684

Fiedler, M. (2012). Officer safety and wellness an overview of the issues. United States Department of Justice. Retrieved from

Glanz, K., Rimer, B. K,.\& Lewis, F.M. (2002).Health Behaviour and Health Education. Theory, Research and practice. San Francisco: Wiley \& Sons.

House, J.S. (1981). Work Stress and Social Support. Reading, Mass: Addison-Wesley.

Impetus (2014, September). Ready for work. Impetus - The private equity foundations. 
Karimu, 0.0. (2015). Effects of the Nigeria police force personnel welfare condition on performance. European Journal of Research and Reflection in Arts and Humanities, 3(1) 26-38. Progressive Academic Publishing, UK

Lakey, B. (2010). Social support: Basic research and new strategies for intervention. In J. E, Maddux \& J.P. Tangney (Eds.) Social Psychological Foundations of Clinical Psychology (pp. 177 - 194), NY: Guildford.

Lakey, B., McCabe, K., Fisicaro, S., \& Drew, J. (1996). Personal and Environmental Determinants of social support. Three generalizability studies. Journal of Personality and Social Psychology, 70, 1270-1280.

Ling, S.M. (2014). An investigation of factors of work stress influence on job stress: moderating social support. Unpublished dissertation submitted to Othman Yeop Abdullah Graduate School of Business, Universiti Utara Malaysia

New World Encyclopaedia (2013). Civilisation.Retrieved 14th May 2016 from http://www.newworldencyclopedia.org/entry/Civilization

Nigeria Police Force (2016). Nigeria Police Force Monthly New Dawn, 7 (13)

Nigeria Police Yearly Report (2010, 2011). http:/www.nigeriapolice.com 2010\& 2011

Omideyi, 0 (2012). Police reforms and restructuring in Nigeria. Village Square. http://www.nigeriavillagesquare.com/olaide-omideyi/police-reforms-and-restructuring- in-Nigeria-part-4.html Onyeozili, E.C. (2005). Obstacles to effective policing in Nigeria. African Journal of Criminology and Justice. 1(1), 3254.

Ray, L. (2016). The importance of being prepared as a police officer. Hearst newspapers. Retrieved 18 February 2016 from work.chron.com/importance-being-prepared-police-officer-10641.html

Scott J.,\& Marshall, G. (2009).Oxford Dictionary of Sociology (3rd Edition.) Oxford: Oxford University Press.

Uchino, B. N. (2009). Understanding the links between social support and physical health: A life-span perspective with emphasis on the separability of perceived and received support. Perspectives on Psychological Science, 4, 236255.

Visen, B., \& Priya (2010). Industrial psychology. New Delhi, New Age International (P) Limited, Publishers

Williams, B. (2002). Fitness in law enforcement. Unpublished thesis submitted to Police Staff and Command, E.M.U. Class \#14

Zimet G.D., Dahlem, N.W., Zimet, S.G., Farley, G.K. (1988). The Multidimensional Scale of Perceived Social Support. Journal of Personality Assessment; 52:30-41. 